\title{
Effects of Pesticides on hormone and enzyme systems of aqua population: a view over Anasagar lake, Ajmer
}

\author{
Sunil Jain ${ }^{1}$, Dr. Gunwant Sharma ${ }^{2}$, Dr. Y.P.Mathur ${ }^{3}$ \\ ${ }^{1}$ HOD (Civil Engg.Deptt.), Govt. Polytechnic College, Ajmer, \\ ${ }^{2,3}$ Professor (Civil Engg .Deptt.),MNIT, Jaipur.
}

\begin{abstract}
Water sources are particularly at risk to contamination by pesticides because of the accumulation and distribution of contaminating substances in sediments of rivers, lakes, and ponds. Potential sources of this impact in water bodies include municipal sewage and agricultural runoff (pesticides and herbicides). The enzyme and hormone disrupting capabilities of pesticides and related chemicals are suspected to be some of the factors contributing to the decline of fish, amphibian and reptile populations of water bodies. In most cases the cause are assumed to result from man-made pollutants in the aquatic environment. The lake Anasagar is a perennial, shallow fresh wetland situated in the heart of Ajmer city. It is degraded because of anthropogenic activities including input of detergents, pesticides and other chemicals due to agricultural activities, sewage disposal and human settlement around the lake. A large area of the catchment of Lake Anasagar is being used for agriculture particularly Trapa bispinosa as the primary cash crop and vegetable crops such as Cauliflower, Tomato, Cabbage, Brinjal, Okra etc leading to input of organo chlorine pesticides in the lake. It was found that water of Anasagar is highly contaminated with these synthetic pesticides. The concentration of organo chlorine was higher in summers than in the rainy season. It has been indicated that many pesticides in the aquatic environment are capable of disrupting the endocrine systems of aqua life. Some pesticides and related chemicals are persistent in the environment and are accumulated in the fatty tissue of organisms and increase in concentration as they move up through the food web. These chemicals are substances that can cause adverse effects by interfering in some way with the body's hormones or chemical messengers and even disrupting the sexual development of aqua population even at extremely low doses, reducing the cholinesterase activity of amphibians and reptiles, causing disease and reproductive failure in fish populations. Concern over the decline of amphibians globally has highlighted the importance of using this group as a bio indicator of environmental contamination and climate change.
\end{abstract}

Key words: pesticides, herbicides, wetlands, bio-indicators.

\section{Introduction}

The pesticides and related chemicals originating from human activity or agricultural farming are discharged directly or indirectly into the receiving waters. The pesticides applied on land eventually find their way to the aquatic environment and thus contaminating it. These are transported to aquatic bodies by run-off, rivers and streams associated with biotic and abiotic macro- particles. The presence of these chemicals in the environment has become a global issue. Pesticides and related chemicals destroy the delicate balance between species and functioning ecosystem producing many physiological and biochemical changes in freshwater organisms by influencing the activities of several enzymes. Variation in the chemical composition of the natural aquatic environment usually affects behavioral and physiological systems of the inhabitants, particularly those of the fish. Hormone-disrupting effects in biota as a result of chemicals are caused by a wide variety of mechanisms. Pesticides and related chemicals are substances that can cause adverse effects by interfering with the body's hormones or chemical messengers, therefore called hormone disruptors or endocrine disruptors as it is the endocrine glands that secrete the hormones. Hormones play a critical role in guiding normal cell differentiation in early life forms and so exposure to endocrine disrupting substances in the egg or in the womb can alter the normal process of development. The pesticides and related chemicals may cause effects in mammalian systems later in life, such as effects on learning ability, behaviour, reproduction and increased susceptibility to cancer and other diseases. Field studies have shown that the reproduction, growth and development of wildlife species, including invertebrates, amphibians, reptiles, fish, birds and mammals may have been impacted by chemicals that interact with the endocrine system. Pesticides at low concentrations may act as blockers of sex hormones, causing abnormal sexual development, abnormal sex ratios and unusual mating behavior. Pesticides can also interfere with other hormonal processes, such as thyroid and its influence on bone development. Biochemical changes induced by pesticidal stress lead to metabolic disturbances, inhibition of important enzymes, retardation of growth and reduction in the fecundity and longevity of the organism. Interference with endocrine hormones affects reproduction, immune function, development and neurological functions in several species of wild animals. These outward symptoms of developmental disruption are 
accompanied by reduced fertility and even sterility in adults, as well as lower hatching rates and viability of off spring. A direct relationship between concentrations of pesticides and related chemicals in fish tissues and depressed hormone concentrations has been established. Disruption of the balance of endocrine hormones during development of young fish can also cause defects of the skeletal system, resulting in deformities and stunted growth. After "Green Revolution", the consumption of pesticides has increased rapidly in India. The high efficiency and lower cost of organo-chlorines pesticides compared with alternative pesticides is the reason for their continuous use in developing countries. Organo-chlorine pesticides have been extensively used for agricultural and vector control purposes in India. Consumption of biota from contaminated aquatic body is considered to be an important route of exposure to Persistent Organic Compounds. Organo- chlorine pesticides are characterized by high persistence, low polarity, low aqueous solubility and high lipid solubility and as a result, they have a potential to bio accumulate in fatty tissue and subsequent magnification of concentration in organisms progressing-up the food chain. Humans, being a final link in the food chain are mostly affected and consequently the general public risk to human health from consumption of such biota. The continued use of organo-chlorine pesticides in developing countries is of international concern due to ability to undergo long distance atmospheric transport, eventually getting deposited in areas far from the point of application.

Many of the pesticides that have been used extensively for long periods in the catchment area of Anasagar Lake are $\mathrm{HCH}$, DDT, Heptachlor and Aldrin. These were found harmful for human beings (neurological disorders, dermatological disorders, renal disorders, gastrointestinal disorders, hematological disorders, reproductive disorders and respiratory problems) and aqua life. These are being widely used in agriculture, as well as in mosquito and other vector control program in the region even after being banned in India. Five sampling sites were selected within the Anasagar Lake from September 2006 to August 2007 for collection of water samples. The samples were taken from $0.3 \mathrm{~m}$ below the water surface in amber colored 1 liter bottle that was rinsed with ethyl acetate and were heated at $250^{\circ} \mathrm{C}$ before use. The residue of organochlorine pesticides were analyzed using a Chemito Gas Chromatograph. A total 60 samples were collected from the five locations and analyzed for organo-chlorine pesticide residues viz. Heptachlor, pp DDT, pp DDE, pp DDD, $\beta-\mathrm{HCH}$ and Aldrin. The average concentration of different organo chlorine residues in various samples analyzed throughout each year which was found within FAO/WHO permissible permissible limits. The average concentration of Heptachlor in various samples was $0.033417 \mathrm{ppm}(<.5 \mathrm{ppm})$ and the range was between 0.004 to $0.068 \mathrm{ppm}$. The concentration of $\beta-\mathrm{HCH}$ in the lake varied from 0.125 to $1.174 \mathrm{ppm}$. The higher concentration of $\beta-\mathrm{HCH}$ may be correlated with its ease availability in the local market. The pp-DDT value varied from 0.026 to $0.0562 \mathrm{ppm}$ and its average value was $0.040217 \mathrm{ppm}(<1.0 \mathrm{ppm})$, while its metabolites ie. pp DDD and pp DDE were reported with range from 0.0102 to $0.0491 \mathrm{ppm}$ and 0.006 to0.0361 ppm, respectively. Due to low cost of DDT and its high efficacy, it has been used as a prime choice of farmers and cultivators in Ajmer region. Although it was banned for agriculture use by the Government of India in 1996, it is still being used by farmers due to improper implementation of Governmental policies and lack of awareness among general public. The Aldrin concentration in the lake was reported in the range of 0.0051 to $0.0268 \mathrm{ppm}$ $(<0.11 \mathrm{ppm})$. The average value of this organo-chlorine pesticide was analyzed to be $0.016883 \mathrm{ppm}$. Data revealed that the residues of these pesticides were found to be significantly high, among which $\beta-\mathrm{HCH}$ was most abundant residue in the Anasagar Lake.

\section{Impact On Aqua Life}

There has been a growing consciousness that amphibian populations have been declining at an alarming rate. A global study was made over 600 amphibian populations and it was found that $53 \%$ decline was in Western Europe, 54\% and 60\% in North and South America respectively and as much as $70 \%$ of the amphibian populations declination in Australia and New Zealand. During the year 2000 and 2004, the number of extinctions in the fish, amphibian, reptilian and mammalian groups increased further. There are 338 species which are considered extincted and another 22 species are considered as in the process of extinction in the world.

Fish species are sensitive to enzymic and hormone disruptors. Chronic exposure to low levels of pesticides may have a more significant effect on fish populations than acute poisoning. Doses of pesticides that are not high enough to kill fish but with may cause subtle changes in behaviour and physiology that impair both survival and reproduction. Liver, kidney, brain and gills are the most vulnerable organs of a fish exposed to the medium containing any type of toxicant. The fish show restlessness, rapid body movement, convulsions, difficulty in respiration, excess mucous secretion, change in colour and loss of balance when exposed to pesticides. The Great Lakes fish are contaminated with chlorinated organic compounds such as PCB (polychlorinated biphenyls), pesticides such asmirex and dieldrin and trace amounts of metals such as lead and mercury. Lake trout extincted in Great Lakes in the 1950swas found to be very sensitive to dioxins and PCBs when exposed as embryos. Several species of salmon introduced into the Great Lakes experienced severely enlarged thyroid glands, an evidence of hormone disruption. Salmon in the Lake Erie show a variety of 
reproductive and developmental problems, for example, early sexual development and a loss of the typical male secondary sexual characteristics, such as heavy protruding jaws and red coloration on the flanks. In fish, endocrine disruptors interrupt normal development and cause male fish to have female characteristics. Pesticides can indirectly affect fish by interfering with their food supply or altering the aquatic habitat, even when the concentrations are too low to affect the fish directly. Other agricultural chemicals are capable of killing salmon and other aquatic animals directly and within a short period of time. Several laboratory experiments show that sub lethal concentrations of agrochemicals can affect many aspects of salmon biology, including a number of behavioral effects. Some pesticides such as organ chlorine and organophosphates are known to cause morphological damage to the fish testis. These also affect female fish in the same way. They cause delayed oocyte development and inhibition of steroid hormone synthesis. Exposure of fish to them has shown to depress protein values in brain, gills, muscle, kidney and liver.

Amphibians are important components of aquatic habitats, especially in tropical regions of the world. The mechanisms responsible for the decline of amphibian populations include chemical pollution from pesticides and fertilizers and global climate change. The health of amphibians can suffer from exposure to pesticides. Because of their semi permeable skin, the development of eggs and larvae in water and the position in the food web, amphibians are prone to adverse effects of waterborne and airborne pollutants in their breeding and aging habitats. Pesticides may affect amphibian populations in a number of ways. They may kill individual amphibians directly or indirectly through alterations in immune or neurological function. Pesticides may also affect amphibian populations by disrupting normal growth and development of the young or by impairing adult reproduction. An extensive research study conducted in Quebec, Canada, shows that hind limb deformities are commonly observed in transformed bullfrogs, green frogs, northern leopard frogs and American toads. Deformity rates tend to be higher at agricultural areas, suggesting that herbicides and pesticides are the likely causes. Fifteen amphibian species have been designated as endangered, threatened or of special concern by the Committee on the Status of Endangered Wildlife Canada due to some threats including chemical contamination. Amphibians are known to be vulnerable to pesticides that are cholinesterase (cholinesterase is a family of enzymes that catalyze the hydrolysis of the neurotransmitter acetylcholine into choline and acetic acid), a reaction inhibitors. Anti cholinesterase pesticides function by binding with this enzyme in animals and disrupting nervous system activity, usually causing death by respiratory failure. Decreased cholinesterase activity can indicate exposure to some commonly used pesticides and can be harmful to wild animals. The normal growth and development of amphibian larvae rely on functional and uncontaminated aquatic systems. It may adversely affect amphibian reproductive processes. Exposure of amphibians to dimethoate, carbofuran and chlorpyifos can alter vitamin A levels and reduce melanogenesis( melanin -producing cells) The effects of sub lethal concentrations are more relevant to amphibian communities because they may directly affect time of and size to transformation or indirectly affect survival .

Globally $42 \%$ of turtle and tortoise species are threatened due to rapidly deteriorating status of fresh water turtles and tortoises in Southeast Asia. The decline in the population of alligator in the Lake Apopka, Florida (USA), is due to contamination by organo chlorine pesticides that emanate from a chemical spill in near area. A number of disturbing abnormalities were recorded alligators, including modifications of enzyme activity, concentrations of sex hormones, abnormal ovarian morphology. The common snapping turtle is the largest freshwater turtle occurring in Canada. Snapping turtle eggs from the Great Lakes contain high concentrations of fat-soluble contaminants which are absorbed while food is being digested. These include PCBs, dioxins, furans and organochlorine pesticides. Abnormal development, such as incidence of unhatched eggs or deformed animals, occurs at the highest rates in the sites which are the most contaminated.

\section{Conclusion}

It is estimated that $70-90 \%$ of ground-applied pesticides and only $25-50 \%$ of aerially-applied pesticides actually reach their target area which can persist in the environment for a number of years causing thyroid dysfunction, decreased fertility, decreased hatching, success birth deformities, metabolic abnormalities, behavioural abnormalities, feminization of males, masculinization of females birds and mammals and aqua life. The remainder is dispelled into the environment where it exposes to wildlife and people. Pesticides can enter non-agricultural landscapes in numerous ways, including direct overspray. It has been found that pesticides and related chemicals are capable of blocking the action of hormones in fish, amphibians and reptiles and causing reproductive dysfunction and abnormal development. They act on target tissues through hormone receptors or nonreceptors, may influence hormone secretion or its clearance from the body. The role of pesticides and related chemicals in amphibian malformations may be of concern due to the high deformity rates associated with sites where agricultural chemicals have been used. These chemicals can be a major threat to fish, amphibians and reptiles and aquatic environment by diminishing productivity and fecundity. Further research is needed to evaluate the effectiveness of alternative and eco friendly pesticides and related chemicals to reduce the effects on fish, amphibian and reptilian populations. Globally, studies need to simultaneously consider the benefits to 
both agricultural and conservation communities; scientists from both communities should provide input to make realistic and informed decisions about the protection and conservation of aquatic biodiversity within agricultural landscapes. The organo-chlorine pesticide residues detected in Lake Anasagar were observed in higher concentration. It was observed that organo-chlorine pesticide residue concentration became high in peak summers due to low quantity of water in the lake, where as in rainy seasons, after the arrival of monsoon, when rain water feeded the lake, the residue levels were comparatively very low due to dilution i.e. excess of water. Thus the biota and other aquatic life of the lake also fluctuate with the changing concentration of organochlorines residues. Due to high efficacy, a periodic monitoring of such persistent pesticides should be instituted so as to obtain information on the environmental quality of the Lake Anasagar.

\section{References}

[1] Radhaiah, V., Girija, M. and Rao, K.J. 1987. Changes in selected biochemical parameters in the kidney and blood of the fish, Tilapia mossambica (Peters), exposed to heptachlor. Bull. Environ. Contam. Toxicol. 39:1006-1011.

[2] Jobling, S., Nolan, M., Tyler, C.R., Brighty, G.C. and Sumpter, J.P. 1998. Widespread sexual disruption in wild fish. Environ. Sci. Technol. 32:2498-2506.

[3] Ewing, R.D. 1999. Diminishing returns: Salmon decline and pesticides. Funded by the Oregon Pesticide Education Network, Biotech Research and Consulting, Inc., and Corvallis, OR. 55 pp.

[4] Kegley, S., Neumeister, L. and Martin, T. 1999. Ecological Impacts of Pesticides in California. Pesticide Action Network, California, USA. pp 99. 5. Murty, A.S. 1986. Toxicity of Pesticides to fish. Vols. I and II. C.R.C Press Inc. 483pp, 355pp.

[5] Jana, S. and Bandy opadhyaya, S. 1987. Effect of heavy metals on some biochemical parameters in the freshwater fish Channa punctatus. Environ. Ecol. 5:488-493.

[6] Haider, S. and Inbaraj, M. 1986. Relative toxicity of technical material and commercial formulation of malathion and endosulfan to a freshwater fish, Channa punctatus (Bloch). Ecotoxicol. Environ. Saf. 11:347-351.

[7] Susan, L., Schantz, S.L., Gasior, D.M., Polverejan, E., McCaffrey, R.J., Sweeney, A.M., Humphrey, H.E.B. and Gardiner, J.C. 2001. Impairments of memory and learning in older adults exposed to polychlorinated biphenyls via consumption of Great Lakes fish. Environ. Health Perspect. 109:605-611.

[8] Arnold, H., Plutra, H.J. and Braunbeck, T. 1995. Simultaneous exposure of fish to endosulfan and disulfoton in vivo: ultrastructure, sterological and biochemical reactions in hepatocytes of male rainbow trout (Oncorhynchus mykiss). Aquat. Toxicol. 33:17- 43.

[9] Kim, D.E. 1998. Endocrine disruption in fish. Kluwer Academic Publishers, London.

[10] Tilak, K.S., Janardhana Rao, N.H. and Lakshmi, J. 1991. Effect of pesticides mixed in different ratios to the freshwater Lareo rohita. J. Ecotoxicol. Environ. Monit.1:49-52.

[11] Goodbred, S.L., Gilliom, R.J., Gross, T.S., Denslow, N.P., Bryant, W.L. and Schoeb, T.R. 1997. Reconnaissance of 17B-estradiol, 11-ketotestosterone, vitellognin, and gonad histopathology in common carp of United States streams: Potential for contaminantinduced endocrine disruption: U.S Geological Survey, Open-File Report, pp. 96-627.

[12] Singh, D.K. and Agarwal, R.A. 1989. Toxicity of piperonyl butoxide-carbaryl synergism on the snail Lymnaea acuminata. Int. Revue ges. Hydrobiol. 74:689-699.

[13] Statham, C.N. and Lech, J.J. 1975. Potentiation of the acute toxicity of several pesticides and herbicides in trout by carbaryl. Toxicol. Appl. Pharmacol. 34:83-87.

[14] Rao, K.R.S.S. and Rao, K.V.R. 1989. Combined action of carbaryl and phenthoate on the sensitivity of the acetylcholinesterase system of the fish. Ecotoxicol. Environ. Saf. 17:12-15.

[15] Rao, K.R.S.S. and Rao, J.C. 1987. Independent and combined action of carbaryl and phenthoate on Adverse effects of pesticides and chemicals 322 snake head, Channa punctatus (Bloch). Curr. Sci. 56:331-332.

[16] Houlahan, J., Findlary, C., Schmidt, B., Meyer, A. and Kuzmin, S. 2000. Quantitative evidence for global amphibian population declines. Nature 404:752-755.

[17] Baillie, J.E.M., Hilton-Taylor, C. and Stuart, S.N. (editors). 2004. IUCN Red List of Threatened Species. A Global Species Assessment. IUCN, Switzerland and Cambridge, UK, pp 191.

[18] Lips, K.R. 1998. Decline of tropical montane amphibian fauna. Conserv. Biol. 12:106-117.

[19] Harfenist, A., Power, T., Clark, K.L. and Peakall, D.B. 1989. A review and evaluation of the amphibian toxicological literature. Technical Report Series No. 61, Canadian Wildlife Service, Ottawa. Bishop, C.A. 1992. The effects of pesticides on amphibians and the implications for determining causes of declines in amphibian population. Proceeding of a workshop on declines in Canadian amphibian populations: designing a national monitoring strategy. Canadian Wildlife Service, pp 67-70.

[20] McDiarmid, R.W. 1992. Standard methods for measuring and monitoring biological diversity of amphibians. Proceeding of a workshop on Declines in Canadian amphibian populations: designing anational monitoring strategy. Canadian Wildlife Service, pp $80-82$.

[21] Ouellet, M., Bonin, J., Rodrigue, J., Des Granges, J.L. and Lair, S. 1997. Hind limb deformities (ectromelia, ectrodactyly) in freeliving anurans from agricultural habitats. J. Wildl. Dis. 33:95-104.

[22] David, S. and Seburn, C. 2000. Conservation priorities for the amphibians and reptiles of Canada. CARCN, 93 pp.

[23] Wang, C. and Murphy, S.D. 1982. Kinetic analysis of species difference in acetylcholinesterase sensitivity to organophosphate insecticides. Toxicol. Appl. Pharmacol. 66:409-419.

[24] Catherine, H. and Gloria, M. 2000. USGS Research finds that contaminants may play an important role in California amphibian declines. US. Geological Survey, MS119 National Center, Reston,VA, USA.www.usgs.gov/public/press/public_affairs/ press_releases/pr1338m.html.

[25] Carey, C. and Bryant, C.J. 1995. Possible interrelations among environmental toxicants, amphibian development, and decline of amphibian populations. Environ. Health Perspect. 103 (suppl 4):13-17.

[26] Kirk, J.J. 1988. Western spotted frog (Rana pretiosa) mortality following forest spraying of DDT. Herpetol. Rev. 19:51-53

[27] Cooke, A.S. 1971. Selective predation by newts on frog tadpoles treated with DDT. Nature 229:275-276.

[28] Crain, D.A. and Guillette, L.J. Jr. 1997. Endocrine disrupting contaminants and reproduction in vertebrate wildlife. Rev. Toxicol. 1:47-70.

[29] Purdom, C.E., Hardiman, P.A., Bye, V.J., Eno, N.C., Tyler, C.R. and Sumpter, J.P. 1994. Estrogenic effects of effluents from sewage treatment works. Chem. Ecol. 8:275-285. 
[30] Grute, C. E, Gilbert, P.L. and Seeley, M.E. 1997. Neurophysiological and behavioral changes in nontarget wildlife exposed to organophosphate and carbamate pesticides: thermoregulation, food consumption, and reproduction. Am. Zool. 37:369- 388.

[31] Keshavan, R. and Deshmukh, P.B. 1984. Vitamin A concentrations in liver and serum of frog, Rana tigrina, treated with DDT and sevin. Indian J. Comp. Anim. Physiol. 2:32-36.

[32] Arias, E. and Zavanella, T. 1979. Teratogenic effects of manganese ethylenebisdithiocarbamate (Maneb) on forelimb regeneration in the adult newt, Triturus cristatus carnifes. Bull. Environ. Contam. Toxicol. 22:279-304.

[33] Boone, M.D. and Semlitsch, R.D. 2001. Interactions of an insecticide with larval density and predation in experimental amphibian communities. Conserv. Biol. 15:228-238.

[34] Jones, P.M., Thurman, E.M., Little, E., Kersten, S., Helgen, J. and Scribner, E.A., 1999. Pesticide and metabolite concentrations in sediments and surface and ground water found at sites where frog malformations are present in Minnesota [abs.]: $7^{\text {th }}$ Symposium on the Chemistry and Fate of Modern Pesticides, Lawrence, KS, USA, September 14-16, 1999.

[35] Clark, E. J., Norris, D. O. and Jones, R. E. 1998. Interactions of gonadal steroids and pesticides (DDT, DDE) on gonaduct growth in larval tiger salamanders, Ambystoma tigrinum. Gen. Comp. Endocrinol. 109:94-105.

[36] Khan, M.Z., Maria, Z. and Fatima, F. 2003. Effect of lambda cyhalothrin (pyrethroid) and monocrotophos (organophosphate) on cholinesterase activity in liver, kidney and brain of Rana cyanophlyctis. Korean J. Biol. Sci. 7:165-168.

[37] Khan, M.Z., Nazia, M., Fatima, F., Rahilla, T. and Gabol, K. 2003. Comparison in the effect of lambda cyhalothrin with permethrin on cholinesterase activity in wildlife species Rana cyanophlyctis and Rana tigrina (Ranidae: Amphibia). Bull. Pure. Appl. Sci. 22A:43-49.

[38] Khan, M.Z., Tabassum, R., Naqvi, S.N.H., Erum, Z., Farhana, T., Ahmad, I., Fatima, F. and Khan, M.F. 323 M. Zaheer Khan \& F.C.P. Law 2003. Effect of cypermethrin and permethrin on cholinesterase activity and protein content in Rana tigrina (Amphibia). Turkish J. Zool. 27: 243-246.

[39] Khan, M.Z. and Ghazala, Y. 2005. Pesticides dependent cholinesterase activity in the brain tissue of Rana cyanophlyctis. J. Exp. Zool. India 8:135- 140.

[40] Guillette, L.J. Jr., Gross, T.S., Masson, G.R., Matter, J.M., Percival, H.F. and Woodward, A.R. 1994. Developmental abnormalities of the gonad and abnormal sex hormone concentrations in juvenile alligators from contaminated and control lakes in Florida. Environ. Health Perspect. 102:680-688.

[41] Guillette, L.J. Jr., Gross, T.S., Masson, G.R., Matter, J.M., Percival, H.F. and Woodward, A.R. 1999. Serum concentration of various environmental contaminants and their relationship to sex steroid concentrations and phallus size in juvenile American alligators. Arch. Environ. Contam. Toxicol. 36:447-455.

[42] Ankley, G.T. and Giesy, J.P. 1998. Endocrine disruptors in wildlife: a weight of evidence perspective. Proceeding from Principal Processes for Evaluating Endocrine Disruption in Wildlife. SETAC Press, pp. 349-367.

[43] Shirose, L., Bishop, C. and Gendron, A. 1995. Amphibians and reptiles in Great Lakes Wetlands: Threats and Conservation. Environment Canada, Catalogue No. En 40-222/4-1996E

[44] Bishop, C.A., Brooks, R.J., Carey, J.H., Norstrom, R.J. and Lean, D.R.S. 1991. The case for a cause effect linkage between environmental contamination and development in eggs of the common snapping turtle (Chelydra s. serpentina) from Ontario, Canada. J. Toxicol. Environ. Health. 33:521-547.

[45] Khan, M.Z., Naqvi, S.N.H., Khan, M.F., Tabassum, R., Ahmad, I., Fatima, F. and Tariq, R.M. 2003. Determination of Induced effect of phytopesticide biosal (Neem based formulation) on cholinesterase activity and protein content in kidney and liver of Calotes versicolor Daudin. J. Exp. Zool. India 6:175-179.

[46] Sengupta, M. and Dalwani, R. (Editors). 2008. Proceedings of Taal2007: The 12 ${ }^{\text {th }}$ World Lake Conference: 360-365. 